\title{
ALGUNOS APORTES DE "ESTIGMA" (1963) AL PENSAMIENTO CRIMINOLÓGICO DE LA SEGUNDA MITAD DEL SIGLO XX*
}

Marcela Parada Gamboa**

Resumen: La teoría del etiquetamiento se superpuso al movimiento en contra de los principios positivistas y etiológicos que estudiaban la reacción y los problemas sociales. El interaccionismo desde el campo criminológico se integró a la Teoría del Etiquetamiento. Aunque no puede hablarse de un discurso uniforme, sí se pueden nombrar algunas características comunes. ERVING GOFFMAN, por ejemplo, presenta una obra rica en aportes sociológicos. Este autor ha sido considerado como un desviado con una continuidad teórica desde el orden de la interacción. De esta manera, y dada la diversidad de

* Este artículo constituye el resultado del trabajo investigativo de la materia Pensamiento Criminológico II adscrito a la Maestría en Criminología de la Universidad Nacional del Litoral en Santa Fé, Argentina.

** Abogada de la Universidad Industrial de Santander, uIS. Especialista en Derecho Penal de la Universidad Autónoma de Bucaramanga, UnAB. Estudiante de la Maestría en Criminología de la Universidad Nacional del Litoral (UNL), Santa Fe, Argentina. Docente investigadora de la Universidad de Pamplona (Pamplona, Colombia). Integrante de los grupos de investigación NUDos de la Facultad de Artes y Humanidades y JUPRo de la misma universidad. Directora del Semillero "Emiro Sandoval Huertas" adscrito al programa de Derecho.E-mail: marcelaparadaga@gmail.com Pamplona, Colombia. Fecha de recepción: 2 de diciembre de 2014. Fecha de modificación: 16 de diciembre de 2014. Fecha de aceptación: 16 de diciembre de 2014. Para citar el artículo: Marcela Parada Gamboa. "Algunos aportes de 'Estigma' (1963) al pensamiento criminológico de la segunda mitad del siglo Xx”. Revista Derecho Penal y Criminología, vol. 35, n. ${ }^{\circ}$ 99, julio-diciembre de 2014, Bogotá, Universidad Externado de Colombia, 2014, pp. 89-112. DOI: http://dx.doi.org/10.18601/01210483.v35n99.04 
conceptos en la obra de GoFFMAN, el principal objetivo es analizar uno de sus libros más importantes: Estigma. La identidad deteriorada. Esta obra, publicada inicialmente en 1963, recoge precisiones vitales para la sociología de la desviación y la criminología en particular.

Palabras clave: interaccionismo, estigma, Teoría del Etiquetamiento, identidad, normalización.

\title{
SOME CONTRIBUTIONS OF "STIGMA" (1963) TO THE CRIMINOLOGICAL THOUGHT OF THE SECOND HALF OF THE TWENTIETH CENTURY
}

\begin{abstract}
Labeling theory was superimposed on the movement against the positivists and etiological principles that studied the reaction and social problems. Interactionism from the criminological field joined Labeling Theory. Although we can not speak of a uniform discourse, it is possible to identify some common characteristics. ERving GofFMAN, for example, presents a work rich in sociological contributions. This author has been considered a target with a theoretical continuity from the order of interaction. Thus, given the diversity of concepts in the work of GoffMAn, this paper analyzes one of his most important books: Stigma. The Spoiled Identity. This work, originally published in 1963, contains vital details for the sociology of deviance and criminology.
\end{abstract}

Keywords: Interactionism, stigma, Labeling Theory, identity, standardization.

\section{INTRODUCCIÓN}

El manejo del estigma es un vástago de algo básico en la sociedad: la estereotipia o el recorte de nuestras expectativas normativas referentes a la conducta y al carácter; la estereotipia está clásicamente reservada para los parroquianos, para los orientales y los automovilistas, es decir, para aquellas personas que caen dentro de categorías sumamente amplias y que pueden ser extrañas para nosotros. ERVING GOFFMAN ${ }^{1}$

En los primeros años de la segunda mitad del siglo xx se evidenció un rechazo a la sociedad opresora que neutralizaba a sus individuos mediante la naturalización de lo existente. Así, desde la academia estadunidense se criticó al Estado de Bienestar y a un modelo científico representado por la sociología estructural funcionalista ${ }^{2}$.

1 Estigma. La identidad deteriorada. Amorrortu, Buenos Aires, p. 72.

2 Anitua, Gabriel Ignacio. Historia de los pensamientos criminológicos. Puesto, Buenos Aires, 2005 , p. 253. 
Estos cambios estuvieron acompañados no solo de nuevos modelos políticos y sociales, sino de importantes virajes culturales en la vida norteamericana. Uno de los campos en que se reconocieron estos procesos fue el de la Criminología. Desde allí se planteó una ruptura con el pensamiento social existente, al cuestionar cada una de las instituciones del discurso criminológico positivista.

Si bien no se conocen las razones para el surgimiento del interaccionismo en el mundo criminológico, algunas respuestas están mediadas por el contexto en que se desarrolló. Durante los años sesenta, la utilización de estas ideas estaba inscrita en una moda sociológica de reconocimiento de los excluidos sociales, y además en la extensión de la educación superior a las clases marginales de la sociedad norteamericana ${ }^{3}$. "Se consideró que el interaccionismo era una sociología existencial con suficiente vitalidad y apertura como para capturar el nuevo demi-monde. [...] Aunque el interaccionismo se aplicaba mucho antes de la vida marginada de 1960, al parecer muchos de los interaccionistas" "4 aceptaron una historia según la cual ellos mismos eran criptodesviados ${ }^{5}$.

El interaccionismo comenzó a tener mayor reconocimiento en el campo académico cuando cuestionó el predominio de TALCOTT PARSONS en la sociología. "Los ensayos teóricos de BLUMER se publicaron en la década de 1960, y fue en esta década cuando los teóricos más jóvenes tomaron en serio la idea de BLUMER de desarrollar enfoques interaccionistas en diversos subcampos empíricos"6. El interaccionismo retomó el individualismo norteamericano y concibió a la realidad social no como algo objetivo, sino como una realidad en donde intervenían decisivamente el individuo y otras formas de interacción social subjetivas ${ }^{7}$.

Sin embargo, los interaccionistas no tenían una unidad de contenido. Poseían un conjunto heterogéneo de ideas que trajo consigo determinados referentes: una lógica de acción y una orientación teórica y metodológica general. "Esta etiqueta provisional funciona a modo de mínimo común denominador -conceptos como microsociología,

3 Downes, David y Rock, PAul. Interaccionismo simbólico. En: Sociología de la deviación. Gedisa, Barcelona, 2011,pp. 261-262.

4 Ibíd., p. 263.

5 Un artículo interesante que detalla esta posición por parte de los interaccionistas cercanos a la sociología de la desviación es el de HowARD BECKER, “¿De qué lado estamos?”, en el cual se establece que no existe neutralidad en los estudios sociológicos. Para BECKER es imposible realizar análisis sociológicos sin tomar partido, es decir, es impensable abordar un problema neutralmente. E indudablemente no hay un cuadro balanceado frente a estos estudios, se toma partido conforme a los lineamientos personales, políticos y sociales, procurando la utilización de las mejores técnicas para demostrar que a pesar de la simpatía, esta se puede probar como falsa. Cfr. BECKER, HOWARD. Estigmatización y conducta desviada. Maracaibo, Universidad de Zulia, pp. 20-30.

6 AleXAnder, JefFrey. Las teorías sociológicas de la Segunda Guerra Mundial. Barcelona, Gedisa, 1992, p. 120.

7 Ob. cit. AnItuA. Historia de los pensamientos criminológicos, cit., p. 257. 
sociologías de la vida cotidiana, enfoque dramatúrgico o sociologías de la situaciónhan sido utilizados para describir a todas o algunas de las aportaciones analizadas por sus autores" 8 . Dentro de esta multiplicad de ideas, algunos autores terminaron por sobresalir en el campo criminológico. Personajes como HowARD BECKER, EDWIN LEMERT, THOMAS ERICKSON, JHON KITSUSE y ERVING GOFFMAN, entre otros, realizaron considerables aportes al pensamiento criminológico contemporáneo.

ERVING GOFFMAN, por ejemplo, presenta una obra rica en aportes sociológicos. Este autor ha sido considerado como un desviado con una continuidad teórica desde el orden de la interacción ${ }^{9}$. Elementos como el análisis de la estructura y los caracteres propios de la interacción cara a cara lo catalogaron como un innovador en su campo $^{10}$. La caracterización en términos esencialmente normativos y de constreñimientos sociales llevó a GOFFMAN a ser visto como un funcionalista ${ }^{11}$.

A la luz de lo anterior, y dada la diversidad de conceptos en la obra de GofFMAN, el principal objetivo del presente trabajo es analizar uno de sus libros más importantes: Estigma. La identidad deteriorada. Esta obra, publicada inicialmente en 1963, recoge precisiones vitales para la sociología de la desviación. El ejercicio representado por este artículo se desarrolla en tres ejes: el primero aborda algunas lecturas y conceptos del interaccionismo simbólico y la teoría del etiquetamiento; el segundo estudia algunas de las relaciones conceptuales del interaccionismo con la obra de Goffman y los principales elementos de Estigma; por último, se exponen las críticas realizadas a la obra referenciada, así como al interaccionismo en general. En el fondo, consideramos que GOFFMAN y su Estigma reinventan esa nueva identidad que se recrea en los contactos mixtos.

\section{EL INTERACCIONISMO, LA REACCIÓN SOCIAL Y LOS DESVIADOS}

El interaccionismo desde el campo criminológico se integró a la Teoría del Etiquetamiento. Aunque no puede hablarse de un discurso uniforme -como ya se señaló-, sí se pueden nombrar algunas características comunes. El interaccionismo desarrollado

8 Guillamón Marrero, IsaAc. Descentrar el sujeto. Erving Goffman y la teorización del sujeto. Revista Internacional de Sociología (RIS), vol. 70, n. ${ }^{\circ}$, mayo-agosto 2012, Instituto de Estudios Sociales Avanzados de Andalucía, p. 312.

9 "El interés de este sociólogo canadiense aunque formado en Chicago, radicaba en realidad en las relaciones de la vida cotidiana. Pero, para percibirlas estudiaría las rupturas a ella, con discapacitados o privados de la libertad. Del mismo modo que prestaría atención a los lapsus o 'meteduras de pata' para extraer las reglas de la interacción social normal” (ANITUA. Historia de los pensamientos criminológicos, cit., p. 359).

10 Herrera, Manuel y Soriano Rosa. La teoría de la acción social en Erving Goffman. Revista Papers de Sociología n. ${ }^{\circ}$ 73, Universidad de Barcelona, 2004, p. 60.

11 Ibíd. 
por MEAD, retomado por BLUMER y consolidado por LEMERT, fue el que terminó por atraer a los autores de la teoría del etiquetamiento ${ }^{12}$. Siguiendo a MEAD, estos autores establecían al Yo como un producto social, en donde la forma en que actuamos y cómo nos vemos no es más que una consecuencia de la forma en que otras personas actúan con respecto a nosotros. Sin embargo, a pesar de su carácter problemático, el Yo social se enraíza firmemente en la interacción con los demás, y es este un hecho social que adquiere importancia en la consideración de la carrera individual ${ }^{13}$. "Estos autores ponen el acento en la naturaleza de las normas sociales y en los rótulos que se aplican a las personas ${ }^{14}$ que contravienen esas normas o la reacción social que las provocan"15.

La teoría del etiquetamiento se superpuso al movimiento en contra de los principios positivistas y etiológicos que estudiaban la reacción y los problemas sociales. De alguna manera, eran relativistas sociológicos, para quienes lo desviado no tenía siempre las mismas características para las personas, y según los cuales lo que se consideraba desviado en determinado tiempo y espacio quizás no siempre había sido as $1^{16}$. Algunas de las preocupaciones centrales para los interaccionistas eran: ¿qué ocurre cuando alguien es identificado y definido como delincuente? ¿Cuáles son los efectos de esta etiqueta de la persona desviada? ${ }^{17}$. Para ellos, el rótulo de desviado, establecido por determinado grupo social o agencia de control, cambia la concepción de una persona respecto de sí misma. En tales casos, los procesos de control social producen una imagen negativa de uno mismo o una reorganización simbólica del yo, en la que la persona se ve como desviada y progresivamente actúa como tal. Así, una persona llega a ser calificada de desviada y termina por aceptar esta carrera de desviación ${ }^{18}$.

Por tanto, la desviación para los interaccionistas es producto de las ideas que las personas tienen respecto de las demás. La desviación es un tipo de descripción utilizada

12 Larrauri, Elena. La herencia de la criminología crítica. Siglo XXI, México, 1992, p. 25.

13 TAYlor, IAn; Walton Paul y Young Jock. La Nueva Criminología: contribución a una teoría social de la conducta desviada. Amorrortu, pp.159-160.

14 Para la Nueva Criminología, la afirmación de que "el control social lleva a la desviación o la crea" se entendió de tres maneras diferentes. Una primera perspectiva estaba dada por que las infracciones no se consideraban conductas desviadas hasta tanto un grupo social no las determinara así. La segunda se desarrolló frente a la reacción de las agencias de control y su influencia en que el individuo desviado practicara reiteradamente esta conducta. Por último, la simple existencia de las agencias de control produce unas constantes tasas de desviación social. Los interaccionistas se ocuparon de la primera y la tercera; de la segunda lo hicieron los etnometodólogos (ibíd., p. 157).

15 Ibíd., p. 157.

16 Esta crítica es una de las fundamentales desarrolladas por la Nueva Criminología, y en ella se plantean a la Teoría del Etiquetamiento los principales problemas de cara al análisis de los desviados.

17 LARRAURI. La herencia de la criminología crítica, cit., p. 28.

18 Ibíd., p. 158. 
en las conversaciones que ordenan la vida social ${ }^{19}$. El objetivo de los interaccionistas consiste en encontrar el significado que configura la actividad social, describiendo los mundos sociales pequeños que construyen una sociedad. El significado más importante es el utilizado por los actores sociales mismos, no el que miran los sociólogos: "el interaccionismo está diseñado para adentrar al observador y a la audiencia tan profundamente como sea posible en las perspectivas que los propios actores tienen sobre los yoes, los actos, y los entornos" 20 .

Los sociólogos de la desviación sugirieron un estudio de los procesos sociales encargados de llevar a cabo la nominación de desviado. Para estos teóricos, si el delito terminaba por ser ese comportamiento definido como tal, quizás ese mismo comportamiento no presentara ninguna característica diferente de otros comportamientos. "La diferencia está en que unos comportamientos son definidos como delictivos y otros no. La desviación no tiene en sí misma una entidad ontológica y no termina por existir independientemente de un proceso de reacción social. No es que el acto sea desviado, es el significado que se le atribuye al acto. Es la reacción social lo que lo define como desviado" 21 . En consecuencia, el delito es una construcción social que requiere de un acto y de una reacción social negativa. El delincuente no es aquel que delinque sino a quien le ha sido atribuida la etiqueta.

Autores como ERIKSON y KITSUSE recuperaron vertientes de la etnometodología y la fenomenología en el estudio de la desviación ${ }^{22}$. ERIKSON estableció a la desviación como un atributo que no estaba inmerso en las formas de comportamiento, sino que estaba dado por el público que directa o indirectamente lo contemplaba. "Por lo tanto, la variable crítica en el estudio de la desviación, será el público antes que el actor, puesto que es aquel y no este, quien determina si una conducta merece o no la etiqueta de desviado" 23 . Es la comunidad la que funda ciertas irregularidades atípicas de la conducta de sus asociados y es ella misma la que decide qué clase de persona es. Por tanto, estudiar de qué modo un sistema social define el papel del desviado a determinados miembros y cómo este los obliga a pasar un tiempo a modo de "puntos finales" como límites del grupo es fundamental en la sociología de la desviación ${ }^{24}$.

19 Downes, DAVID y Rock, PAUL. Interaccionismo simbólico. En: Sociología de la deviación, pp. 270274.

20 Ibíd., p. 264.

21 LARRAURI. La herencia de la criminología crítica, cit., p. 28.

22 GARFINKEL es quien recupera este concepto. Para el año de 1956 publica un artículo importante en la sociología de la desviación. En este, define cómo las ceremonias de degradación terminan por humillar al actor, situándolo en un nivel inferior y dotándolo con una nueva identidad. En dicho artículo quiso demostrar que en las sociedades modernas este tipo de ceremonia de degradación se había institucionalizado en un cuerpo de profesionales. Cfr. ibíd., pp. 40-41.

23 ERIKSON, KAI. Estigmatización y conducta desviada. Maracaibo, Universidad del Zulia, 1962, p. 41.

24 Ibíd., p. 50. 
La desviación debe estudiarse desde el lugar del diferente, del desviado, y se ha de analizar cómo estos lenguajes se ubican durante el proceso de desviación.

Para KiTSUSE analizar las conductas establecidas por los miembros del grupo, la comunidad o la sociedad, y de qué manera estas organizan y activan las reacciones sociales, inevitablemente termina por incorporar el punto de vista de aquellos que son definidos en la conducta desviada ${ }^{25}$. La desviación es un proceso en el cual los miembros de un grupo, comunidad o sociedad interpretan a los individuos que así se comportan, con determinado tipo de desviación, dándoles un trato que ellos consideran como apropiado. Ese tratamiento es dado mediante el lenguaje ${ }^{26}$.

De otra parte, LEMERT desarrolló la distinción entre dos clases de desviación: la primaria y la secundaria. Para este autor, es necesario establecer dos tipos distintos de sistemas de investigación. El primero está referido a cómo se origina la conducta desviada. El segundo se enfoca en cómo los actos desviados se vinculan simbólicamente con las personas. Esta división entre desviación primaria y secundaria es fundamental en la comprensión de la sociedad moderna. Por esto,

... una teoría sociológica de la desviación ha de enfocar específicamente las interacciones que no sólo definen la conducta como desviada, sino que también organizan y activan la aplicación de sanciones por individuos, grupos o instituciones. En la sociedad moderna, la diferenciación socialmente significativa entre desviados y no desviados depende cada vez más de circunstancias contingentes de situación, lugar, antecedentes, sociales y personales y agencias de control social organizadas de forma burocrática ${ }^{27-28}$.

De esta manera, los interaccionistas rescataron herramientas de la sociología para su introducción en el análisis de las conductas desviadas. Se trataba de un juego de intercambios que ordenaba a la desviación y a los desviados como centro del pensamiento criminológico. "El interaccionismo es algo renuente a basarse en descripciones esquemáticas del control social. En cambio, vuelve la sociología al análisis

25 Kitsuse, John. Estigmatización y conducta desviada. Universidad de Zulia, Maracaibo, 1962, p. 54.

Un elemento fundamental para los etnometodólogos es el lenguaje. GARFINKEL establece que la etnometodología es aquel análisis del sentido común, los procedimientos y consideraciones en donde las personas de una sociedad se dotan de sentido y actúan en las circunstancias en que se encuentran. Este autor toma el concepto de Schütz de "el actor sabe cuándo actúa”. Así, las construcciones típicas no son adquiridas por la experiencia personal, sino que son creadas por el lenguaje. GARFINKEL, establece la necesidad de suspender la creencia en la objetividad de las cosas para ver cómo estas son construidas. Cfr. LARRAURI. La herencia de la criminología crítica, cit., pp. 42-47.

27 Para LEMERT, dentro de este proceso de desviación aparecen los signos como caracterizaciones abstractas y ambiguas. Así, cuando alguien termina por ser catalogado como desviado se le aplican una serie de símbolos en su definición. 
detallado de acontecimientos específicos. Hay temas generales que efectivamente dominan ese análisis, pero se considera que tienen el carácter de leyes de hierro" 29 . Un aporte esencial del interaccionismo fue la ampliación de la tarea y la complejidad de la criminología, al insistir en el papel creativo desempeñado por los outsiders en la producción de la desviación ${ }^{30}$.

\section{2. “ESTIGMA" Y SU RELACIÓN CON EL INTERACCIONISMO}

Para GofFman el interaccionismo nunca existió. Para él, los estudiantes que trabajaron con BlumMER, WAGNER, etc. se consideraban a sí mismos como sociólogos de las profesiones o de las relaciones industriales, no como interaccionistas. "El interaccionismo simbólico no tiene realidad: es sólo una etiqueta que ha conseguido imponerse. La gente como usted [refiriéndose al entrevistador] se inventa un movimiento donde no hay más que individuos"31.

Pero es en el mundo de las relaciones cara a cara en donde el orden de la interacción actúa, donde GOFFMAN desarrolló su trabajo de 1963. Dentro del espacio cara a cara existían dos tipos fundamentales de reglas. Por un lado estarían las convenciones habilitadoras, por otro, las normas y valores que los individuos aceptan intrínsecamente como justas. Fue precisamente en el plano de esa aceptación normativa que GOFFMAN intentó correr el velo de las apariencias para arrojar luz sobre las reglas y los mecanismos de aceptación e interpretación, y ello en su obra Estigma. La identidad deteriorada.

El término 'estigma' proviene de los griegos, quienes lo utilizaron para exhibir algo malo y poco habitual. El estigma ${ }^{32}$ se entendía como la referencia que se hacía a un atributo profundamente desacreditador en donde era urgente un lenguaje de relaciones. "Un atributo que estigmatiza a un tipo poseedor, puede confirmar la normalidad de otro y, por consiguiente, no es ni honroso, ni ignominioso en sí mismo" 33. La utilización del término 'estigma' implicaba una doble perspectiva: la del desacreditado y la del desacreditable. Para el primero la condición de estigmatizado era conocida por todos o estaba expuesta de manera evidente. Para el segundo, la situación del estigmatizado no estaba expuesta ni era conocida por aquellas personas que lo rodeaban. En esta condición -la del estigmatizado y del

29 Downes y Rock. Interaccionismo simbólico, cit., p. 280.

30 Ibíd., p. 275.

31 WinkIn, Yves. Entrevista con ERving GOFFMAN [1977]. En: Los momentos y sus hombres. Barcelona, Paidós, 1991, p. 211.

32 El estigma es una relación especial entre atributo y estereotipo. Se entiende como atributo un estigma con un efecto desacreditador amplio, que constituye una serie de discrepancias amplias entre la identidad social virtual y la identidad social real. Cfr. GofFMAN. Estigma. La identidad deteriorada, p. 14-15).

33 Ibíd., p. 15. 
estigmatizante- era fundamental la reacción social que las personas normales tenían frente a este sujeto ${ }^{34}$.

Así, GoFFMAn recogió el andamiaje fundamental del interaccionismo, al volcar su atención sobre la reacción social frente a las personas estigmatizadas. Las personas normales ${ }^{35}$-las no estigmatizadas- adoptaban unas actitudes conocidas de discriminación, inferioridad, de justificación del peligro que el estigmatizado representaba. "Por lo general, parece cierto que los miembros de una categoría social sustentan sólidamente un modelo de opinión que, según su parecer y el de otros sujetos, no les es directamente aplicable"36. De esta forma, había una expectativa difundida de aquellos que pertenecían a una categoría ${ }^{37}$ dada, en donde el individuo estigmatizado trataba de sostener las mismas creencias que las personas normales. Los estigmatizados asumían su calidad de diferente y al hacerlo, intentaban normalizar estas prácticas.

"Un individuo incurre particularmente en sospechas cuando observa que su conducta difiere de la conducta común de los miembros del grupo a que pertenece"38. Bajo el entendido de que el individuo estigmatizado trata a toda costa de iniciarse en un proceso de normalización, GOFFMAN estableció algunos elementos que el sujeto estigmatizado utiliza para sentirse normal. Estas acciones se dividen en tres: la primera es la de aceptación, señalada como una situación vital del sujeto estigmatizado; la segunda es la de intentar corregir su condición de manera indirecta, dedicando un gran esfuerzo al manejo de áreas que para él se consideraban inaccesibles; por último, se trata de romper con la idea de realidad utilizando una interpretación no convencional acerca del carácter de su identidad social ${ }^{39}$.

El principal objetivo de Estigma era estudiar la reacción de las personas normales y los estigmatizados cuando entran en contacto, esto es: los contactos mixtos. Se trata

34 Ibíd., p. 16.

35 Para Goffman los normales son todas aquellas personas que no se apartan negativamente de las expectativas particulares que están en discusión.

36 Ibíd., p.18.

37 Uno de los principales aportes de GOFFMAN a la sociología de la desviación fue el término categoría. Este se desarrolla en el momento de la interacción con otras personas. A cada categoría corresponde una identidad determinada, ya sea una identidad social virtual o una identidad social real. "El término categoría puede ser perfectamente abstracto, puede ser aplicado en cualquier conjunto, en este caso a personas que poseen un estigma particular. Gran parte de los que se incluyen dentro de una determinada categoría de estigma, bien pueden referirse a la totalidad de los miembros con el término grupo o un equivalente, tal como nosotros, nuestra gente": GofFMAN. Estigma. La identidad deteriorada, p. 38. Cuando un miembro de una determinada categoría entra en contacto con otro, ambos pueden estar dispuestos a modificar su trato mutuo por creer que tanto el uno como el otro pertenecen al mismo grupo.

38 KiTsuse. Estigmatización y conducta desviada, cit., p. 60.

39 Goffman. Estigma. La identidad deteriorada, cit., pp. 22-23. 
de momentos en los cuales los normales y los estigmatizados se encuentran en la misma situación, "cuando hay una presencia física inmediata de ambos, ya sea en el trascurso de una conversación o en la simple co-presencia de una reunión informal" 40 . Estos contactos terminan por establecer a la interacción como una incertidumbre. Para GofFman era este el espacio del que "debía ocuparse la sociología de la desviación", siendo que es allí donde ambas partes enfrentan directamente las causas y los efectos del estigma.

La importancia a este tipo de contactos mixtos radicaría en la idea de que generalmente esta respuesta por parte de las personas normales desarrolla una reacción, no solo del estigma mismo, sino de su cualidad, de su escala y de su contexto. En algunas ocasiones esta puede ser normalizada y acomodada dentro de la trama de vida aceptada. Pero es solo cuando resulta inexplicable causa desorden, es dañina o amenazante, que surge una acción crítica. "Las crisis se producen cuando los demás no pueden o no están dispuestos a lidiar con ella. Su precipitación depende de las ideas que se tengan sobre lo que es correcto y lo que es dañino, la organización social de la audiencia y la apreciación de las posibles soluciones" ${ }^{11}$. En este tipo de contactos mixtos no todo está bien. Hay situaciones en las que personas normales tratan al individuo como alguien mejor de lo que se merece o como alguien peor de lo que se piensa que es ${ }^{42}$. Si alguna de estas actitudes no es asumida por las personas normales, se presenta al individuo estigmatizado como una no-persona. "[L]a atención se aleja de manera furtiva de los blancos obligatorios, y aparece la conciencia del yo y la conciencia del otro, expresada en la patología de la interacción"43_44.

\subsection{Los primeros contactos: la aceptación y el rechazo}

De otra parte, la influencia de la etnometodología se hizo presente en Estigma de la mano de GARFINKEL. Autores como LEMERT, BECKER y desde luego GoFFMAN reconstruyeron en sus textos - con algunas variaciones- el concepto de normas constitutivas. Para LEMERT, por ejemplo, las normas constitutivas representaban especificaciones de conductas definidas, de criterios respecto de las posibles situaciones, número de participantes y de orden de la acción que un individuo suponía habría de elegir por él y por la interacción social. "Las reglas constitutivas pueden descubrirse como

40 Ibíd., p. 26.

41 Downes y Rock. Interaccionismo simbólico, cit., p. 274.

42 Un ejemplo claro de este rechazo - aceptación del grupo social- se encuentra planteado en KITSUSE. Para él, cuando la comunidad decide imponer una sanción a un individuo determinado, no es un simple acto de censura. Es -en definitiva- un claro rito de transición, que lo aleja de sus anteriores funciones dentro de la normalidad y lo define en su calificación de desviado. Cfr. KiTSUSE. Estigmatización y conducta desviada, cit., p. 46.

43 Aunque el texto es rico en citas y referencias bibliográficas. La idea de patología social de LEMERT es retomada en varias ocasiones.

44 Goffman. Estigma. La identidad deteriorada, cit., p. 33. 
guías de interacción en el decurso tanto de los acontecimientos diarios como de los juegos" 45 . En ciertas situaciones sería imposible determinar, examinando meramente sus características exteriores, qué es lo que se considera como una conducta normal o desviada. Para esto, es necesario saber qué tipo de reglas constituyen la base de la interacción social y en qué punto se encuentran los participantes dentro de una secuencia de interacción.

Dos aspectos fundamentales en el ejercicio de estas normas constitutivas son la violación y la normalización de estas reglas. La primera establece que cuando se violan estas reglas el contexto se puede tornar algo confuso, llevando a adoptar ciertas situaciones: una es el retraimiento de las personas, y otra, una nueva definición en términos de significados alternativos de lo que es normal o aceptable. La normalización de las reglas se realiza entre personas que confían unas en otras o que están vinculadas por derechos mutuos - tal es el caso de la familia, los grupos de amigos, las relaciones comerciales y profesionales recíprocas-, o bien vinculadas por lazos informales desarrollados dentro de organizaciones formales ${ }^{46}$. De allí la generación de ciertos lazos de confianza en el momento de la interacción social. Los estigmatizados asumen su calidad de diferentes y al hacerlo, uno de estos elementos es tratar de normalizarse.

En este sentido de la normalización, GOFFMAN puso de manifiesto los problemas que acarrea para el estigmatizado el deterioro de su identidad, ya se trate de una identidad virtual o de una identidad real del individuo ${ }^{47}$. En el espacio de identidad social, el estigmatizado pasa a ser una persona desacreditada frente a un mundo que no lo admite; pero paralelamente a esto, existen otro tipo de personas que pese a sus atributos lo aceptan. "Hay gente sensible dispuesta a adoptar su punto de vista en el mundo y a compartir con él el sentimiento de que es humano y esencialmente normal, a pesar de las apariencias y de sus propias dudas" 48 . De ahí que se establezcan dos tipos de personas en los contactos mixtos: el igual ${ }^{49}$

45 LEMERT. Estigmatización y conducta desviada, cit., p. 100.

46 Ibíd., p. 101.

47 "Cuando fijamos nuestra atención en el defecto de la persona estigmatizada (por lo general nuestra vista) -cuando, en suma, no se trata de una persona desacreditable sino desacreditada-, es posible que esta sienta que el estar presente entre los normales la expone, sin resguardo alguno, a ser invadida en su intimidad": GofFMAn. Estigma. La identidad deteriorada, cit., p. 30.

48 Ibíd., p. 34.

49 El primero de ellos compartía el estigma. "Entre iguales, el individuo estigmatizado puede utilizar su desventaja como base para organizar su vida, pero para lograrlo deberá resignarse a vivir en un mundo incompleto" (ibíd., p. 35). Un elemento caracterizador de estos representantes era el de convencer al público para que aplicara un rótulo social más flexible con la categoría en cuestión. Eran personas estigmatizadas que tenían mayores oportunidades de expresar lo que sentían, estaban más y mejor relacionadas que el resto de sus compañeros, descubriendo - al cabo de un tiempo- que este tipo de actividades lo absorbía el día entero. Además, existía una profesionalización de este tipo de personas, y cuando esto se llevaba a cabo se formulaban dos observaciones: la primera, que estas 
y el sabio ${ }^{50}$. Estos dos tipos de categorías dan cuenta de algo muy específico: la relación entre ellos es bastante complicada. La persona que tiene un defecto puede sentir que en cualquier momento es posible un retorno al estado anterior (el de rechazo), particularmente cuando las taras disminuyen y la dependencia hacia ellos aumenta.

Ahora bien, la misma tendencia del estigma a difundirse en estos contactos mixtos, explica por qué muchas relaciones por parte de los estigmatizados se evitan, retrotraen o no perduran en el tiempo. "Las personas que tienen un estigma aceptado, suministran un modelo de normalización, mostrando hasta dónde pueden llegar los normales cuando tratan a un individuo normalizado como si no lo fuera. (La normalización es distintiva de la normificación, o sea, el esfuerzo que realiza el individuo estigmatizado para presentarse a sí mismo como una persona corriente, aunque oculte necesariamente su defecto)" 51 . De esta manera, para entender la diferencia no se debe mirar lo diferente sino lo corriente. Por ende, una de las condiciones básicas para la vida social es que todos sus integrantes compartan un conjunto único de expectativas. Cuando estas se infringen, una regla las restaura, ya sean agencias de control ${ }^{52}$, o el mismo culpable repara el daño ${ }^{53}$.

Las normas tratadas en Estigma se relacionan con la identidad o el ser, y pertenecen a un género especial, son normas de identidad. Tanto el éxito como el fracaso del mantenimiento de dichas normas tienen un efecto directo sobre la integridad psicológica del individuo. Por consiguiente, es un problema que involucra la condición del individuo, no su voluntad, es una dificultad de ajuste, no de sumisión. Los valores de identidad generales de una sociedad no están firmemente establecidos y sin embargo tienen algún tipo de proyección sobre los encuentros que se producen ${ }^{54}$.

convertían el estigma en una profesión. La segunda, que estas personas que representaban a la categoría del estigmatizado tenían una infinidad de parcialidades un su exposición (ibíd., pp. 39-43).

50 Estas eran personas normales que por alguna situación en particular estaban íntimamente ligados a la vida de los estigmatizados. "Las personas sabias son los hombres marginales ante quienes el individuo que tiene un defecto no necesita avergonzarse ni ejercer un autocontrol, porque sabe que a pesar de su imperfección será considerado como una persona corriente" (ibíd., p. 44). GofFMAN clasificó a las personas sabias en dos grupos. El primero, el de las personas cuya sabiduría provenía de actividades en un establecimiento, satisfaciendo tanto las necesidades de quienes tenían un estigma particular como los llamados que la sociedad adopta respecto de estas personas. Y un segundo tipo de personas sabias, esto es, el de las que se relacionan con un individuo estigmatizado a través de la estructura social, permitiendo que en algunas ocasiones la sociedad considere al estigmatizado y al sabio como una sola persona (ibíd., pp. 45-46)

51 Ibíd., p. 47.

52 El término 'agencia de control' es tomado de GIDDENS. Aunque este concepto no fue desarrollado en la Sociología de la Desviación, algunos autores lo utilizan en sus obras. GofFMAn, por ejemplo, la entiende como un actor determinado que toma partido en el ejercicio interpretativo.

53 Ibíd., p. 160.

54 Goffman. Estigma. La identidad deteriorada, cit., p. 161. 
"Lo implicado no son tan solo normas relativas a atributos de estatus algo estáticos. El problema no es simplemente la visibilidad, sino la intrusión; esto significa que la imposibilidad de sustentar normas menores, "puede tener un efecto muy penetrante sobre la aceptabilidad del culpable en situaciones sociales" 55 .

Atendiendo a las normas de identidad se plantea la carrera moral del estigmatizado como punto de partida para la normalización. En este ejercicio existen dos procesos de naturalización del estigma. El primero es aquel en donde la persona estigmatizada aprende a incorporar el punto de vista de los normales, adquiriendo las creencias relativas a la identidad propia de la sociedad. En el segundo, se aprende que se tiene un estigma particular y, por ende, las consecuencias de poseerlo. Ahora, este tipo de socializaciones morales de los estigmatizados crean una serie de pautas que distinguen las carreras morales accesibles a los desviados ${ }^{56}$. Las normas de identidad poseen tanto divergencias como ajustes. De esta manera, al interior de estas normas aparecen implicados ciertos elementos: el encubrimiento y el enmascaramiento. Estos dos dan una aplicación especial de las artes en el manejo de la impresión, en donde el individuo ejerce un control estratégico sobre su propia imagen. Además de una cooperación tácita entre normales y estigmatizados, "los demás tienen buen cuidado de respetar su secreto, pasan por alto la revelación o restan importancia a las pruebas que descubren su secreto; estos otros, a su vez, pueden permitirse ampliar su cautela porque el estigmatizado se abstendrá voluntariamente de reclamar una aceptación más allá de los límites que los normales consideran cómodos" ${ }^{57}$.

\subsection{La construcción de la identidad social y personal}

Ahora bien, dentro de este proceso de normalización el individuo estigmatizado tiene varias posibilidades. Una de ellas es aquella consistente en la colaboración que presta a los normales al actuar como si su diferencia no influyera. Otra, radica en que este tipo de diferencias no se revelan inmediatamente en la sociedad ${ }^{58}$. "El problema

55 Ibíd., p. 162.

56 La primera pauta es la que involucra a los miembros que tienen un estigma innato y son socializados dentro de una situación desventajosa. La segunda pauta se refiere a la posibilidad de que el entorno familiar le construya una cápsula efectiva a su joven miembro para protegerlo. Una pauta más se relaciona con las personas que en determinado momento de su vida fueron víctimas de un estigma o se reconocieron como personas desacreditables. Ellas poseen cierta ventaja, en tanto son personas que han realizado un detallado aprendizaje de lo normal y de lo estigmatizado, mucho tiempo antes de tener que considerarse a sí mismas como personas estigmatizadas. Por último, se encuentran los sujetos socializados inicialmente en una comunidad alienada, en donde debieron aprender una segunda manera de ser. Para GofFman, a pesar de ilustrar esta carrera moral del estigmatizado, es determinante analizar la fase de experiencia durante la cual este sujeto aprende que es portador de un estigma, porque es allí en donde se establecen nuevos tipos de relación con otros estigmatizados (ibíd., pp. 49-53).

57 Ibíd., p. 163.

58 He aquí la caracterización del desacreditado y desacreditable nombrada anteriormente. 
no consiste en manejar la tensión que se genera durante los contactos sociales, sino más bien en manejar la información que se posee acerca de su deficiencia" ${ }^{2}$. De esta manera, la información social producida dentro de los contactos mixtos sería un elemento fundamental que permite identificar los signos, símbolos e imágenes de un individuo en particular.

GOFFMAN, conectado a Estigma con la importancia de los signos escritos en su primer trabajo de 1959 (La presentación del Yo [Self] en la vida cotidiana) ${ }^{60}$, establece que esa información social producida confirma lo que otros signos nos dicen acerca del individuo. Por tanto, los símbolos son los portadores de la información social que terminan por completar la imagen que se tiene en relación con un individuo de manera segura y redundante. Aunque existe una clara diferenciación de los símbolos ${ }^{61}$, estos, en líneas generales, permiten que un sujeto comprenda a una persona que conoce, ya sea mediante una comparación entre claves acerca de la conducta o mediante su experiencia previa de cómo se comportan otras personas ${ }^{62}$. De este modo, a través de la información social reflexiva y corporizada se valora la identidad de un individuo. Por tanto, las consecuencias de esa presentación pública tienen grandes repercusiones en la vida del sujeto estigmatizado. Este proceso de visibilización constituye un factor determinante en la construcción de la identidad social. Aunque en algunas ocasiones esa visibilidad es confundida con algún "estigma de su conocimiento", o con imposiciones por la fuerza, lo fundamental es que esas elaboraciones -objetivas o no- están dirigidas a la esfera vital del individuo estigmatizado.

Al mismo tiempo que la identidad social, la identidad personal juega un papel decisivo en Estigma. Para GofFMAN la identidad personal está referida a dos caracterizaciones de unicidad. Así, tanto las marcas positivas o soportes de la identidad como la combinación de la historia vital adherida al individuo hacen parte de este concepto. "La identidad personal se relaciona con el supuesto de que el individuo puede diferenciarse de todos los demás y que alrededor de este medio de diferen-

59 GofFman. Estigma. La identidad deteriorada, cit., p. 61.

60 Aunque mucho se ha escrito sobre una de las obras más trascendentales de GoFFMAN, la idea general de este trabajo es presentar el modelo dramatúrgico de la sociedad. La vida es un teatro representado con público y actores. Así la dramaturgia es un ritual, que crea símbolos con una fuerte carga moral. Cfr. JuAN JosÉ CABALLERO. La interacción social en el pensamiento sociológico de ERVING Goffman. Revista Espacios Públicos, vol. 14, n. . 31, mayo/agosto, Unam, 2011, p. 127.

61 Existen varias clases de símbolos. Uno de ellos es el denominado símbolo de estatus, que construye un reclamo de prestigio, honor y posición de clase deseada. Una segunda clase es el símbolo de estigma, en el cual se reunen todos los signos efectivos que llaman la atención sobre la "degradante incongruencia de la identidad". Otra es la del símbolo desidentificador, que establece la imagen de la persona estigmatizada tal cual como ella quiere. Algunos símbolos terminan por cumplir una función informativa, y se denominan signos ilustrativos. Otros, son los creados expresamente por el hombre para transmitir información social, como es el caso de las insignias militares. Cfr. GOFFMAn. Estigma. La identidad deteriorada, cit., pp. 63-65.

62 AleXAnder, JefFrey. Las teorías sociológicas de la Segunda Guerra Mundial, cit., p. 141. 
ciación se adhieren y se entrelazan hechos sociales de una única historia continua, que se convertirá luego en una melosa sustancia en la cual pueden adherirse otros hechos biográficos" ${ }^{63}$. Por tanto, el manejo del estigma influye en el hecho de que conociera o no personalmente al individuo estigmatizado desarrollado en la vida pública del sujeto y en la construcción de su identidad.

Algunos elementos como la biografía tuvieron un despliegue importante dentro del concepto de identidad personal. Esta apareció -dentro de Estigma-, siguiendo las sugerencias de GARFINKEL ${ }^{64}$, como punto nodal en la exposición del individuo estigmatizado. La biografía sería la historia en la cual se construye a un individuo, otorgándole limitaciones definidas en la forma como este elige presentarse. La costumbre dio por supuesto que las personas solo tienen una biografía establecida por las normas. Estas normas relativas a la identidad social corresponden a una serie de repertorios que posee cualquier individuo. "Las normas relativas a la identidad personal no pertenecen, sin embargo, a la esfera de combinaciones lícitas de los atributos sociales, sino más bien al tipo de control de información que el individuo puede ejercer apropiadamente" ${ }^{65}$. Para manejar la identidad personal es necesario que el individuo sepa a quiénes debe dar una información abundante y a quiénes una información mínima. Por consiguiente, necesita de una memoria, de una explicación exacta y rápida de los hechos de su pasado, de una biografía.

De esta manera, la identidad personal y la identidad social recogen la visión que el individuo tiene de los demás. La división se establece entre los que saben y los que no saben respecto del estigmatizado. Los que saben, son aquellos que tienen una identificación personal del individuo; con solo verlo u oír su nombre pueden poner en juego la información. Los que no saben, son aquellos para quienes el individuo es totalmente extraño, alguien de quien no se ha iniciado una biografía personal ${ }^{66}$. Así, para GoFFMAN la identidad social considera el proceso de estigmatización, mientras que el concepto de identidad personal atiende al control de la información ${ }^{67}$ respecto del estigma. Esta construcción de una imagen pública de una identidad social y personal está mediada por una serie de acontecimientos ${ }^{68}$, que termi-

63 Goffman. Estigma. La identidad deteriorada, cit., p. 79.

64 Un análisis centrado en la importancia del lenguaje y en las construcciones subjetivas.

65 Ibíd., p. 86.

66 Ibíd., p. 89.

67 Este es un elemento fundamental en la construcción del sujeto estigmatizado. A medida que pasa el tiempo, los sujetos, en sus interacciones, comienzan a conocer más sobre la persona, y así tienen más oportunidades de desacreditar a quien conocen. De esta manera, algunos individuos comienzan una aplicación de técnicas de encubrimiento que están directamente relacionadas con la información que se maneja en los contactos mixtos.

68 Estos acontecimientos, en GofFMAN, están relacionados con el manejo de la información. Técnicas como el ocultamiento y el chantaje plantean un estudio interesante respecto de los lugares de desarrollo del estigma. 
nan por establecer esa apariencia dramática resaltada en sus obras anteriores a $L a$ identidad deteriorada.

\subsection{La desviación normal: Un concepto final}

Ahora bien, se pueden comprender mejor este tipo de identidades -la social y la personal- si se tiene en cuenta el concepto formulado por Erikson y denominado la identidad del yo. En él, el sentido subjetivo se alcanza como un resultado de diversas experiencias sociales por las que atraviesa el sujeto ${ }^{69}$. "La identidad social y la personal forman parte, ante todo, de las expectativas, definiciones que tienen otras personas respecto del individuo cuya identidad se cuestiona"70. De esta manera, GoFFMAN describe el esfuerzo y las estrategias que activan los individuos para presentar una imagen "idealizada" de sí mismos, esto es, ventajosa para ellos y veraz para los otros ${ }^{71}$.

La identidad del yo, entonces, se presenta como aquella posibilidad de interacción del individuo con el estigma. Esto es, como lo que siente el individuo con relación al estigma y a su manejo. "El individuo construye una imagen de sí a partir de los mismos elementos con los que los demás construyen al principio la identificación personal y social de aquel, pero se permite importantes libertades respecto de quien las elabora"72. El individuo estigmatizado logra definirse como igual a cualquier otro ser humano, en tanto que al mismo tiempo es definido por él mismo y por quienes lo rodean como un individuo marginal. En su intento por su normalización crea códigos a los cuales trata de adherir. Las construcciones de estos parámetros terminan por ser concedidas únicamente al individuo estigmatizado.

Dentro de esas categorías de normalización se encuentra algo vital en la interacción del individuo: el grupo. Este, entendido como aquella unidad de individuos con una posición semejante o estratificada, permite plantearlo en dos vertientes: las alienaciones endogrupales y las alienaciones exogrupales. Las primeras están referidas en un plano de igualdad, de estigmatizados. Para él, este es su grupo verdadero: aquel que sufre las mismas carencias que él por tener un mismo estigma. "Su grupo verdadero, es en realidad la categoría que puede servir para su desacrédito"73. Por otro lado, las alienaciones exogrupales hacen referencia a la interacción entre las personas normales y una sociedad mucho más amplia, con contenidos como el buen ajuste y la concepción de una normalidad fantasma ${ }^{74}$.

69 ERIKSON, KAI. Notas sobre la sociología de la desviación.

70 GofFman. Estigma. La identidad deteriorada, cit., p. 135.

71 Herrera, Manuel y Soriano, Rosa, La teoría de la acción social en ERVInG Goffman, cit., p. 63.

72 Goffman. Estigma. La identidad deteriorada, cit., p. 136.

73 Ibíd., p. 143.

74 En la estrategia del buen ajuste, los normales terminan sugiriéndole al desviado una aceptación natural, una aceptación de él mismo y de los demás. Es decir, se habla de una aceptación fantasma 
"El endogrupo y el exogrupo presentan al individuo estigmatizado una identidad del yo, el primero con una fraseología principalmente política, el segundo psiquiátrica". En cada uno de estos grupos se le dice al individuo estigmatizado que es un ser humano como cualquier otro, y que es imprudente encubrirse o abandonar a su grupo. En esta aceptación se le plantean una serie de contradicciones al estigmatizado, en donde se le indica al mismo tiempo que es igual a cualquier otro y que no lo es. "Esta contradicción y esta burla son su suerte y su destino". Así, el estigmatizado está en una constante búsqueda de lo que debe pensar acerca de sí mismo, de su propia identidad del yo y de la construcción de una imagen pública en medio de códigos y técnicas de ocultamiento y aceptación.

"El manejo del estigma es un rasgo general de la sociedad, un proceso que se produce dondequiera que existan normas de identidad. El rol del normal y el rol del estigmatizado son partes del mismo complejo, recortes de una misma tela estándar"75. De esta manera, el manejo y apropiación del estigma da lugar a dos cosas bastante claras. Por un lado, las personas que poseen estigmas diferentes se encuentran en una situación similar y responden de manera parecida. Por otro, tanto el normal como el estigmatizado tienen las mismas características mentales que todos dentro del grupo social. Así, atender al manejo del estigma se da en todos los campos de contactos mixtos en los que se involucran los sujetos.

Para GofFman a la persona desviada debería llamársela desviada normal, esto en la medida que su situación sea analizada dentro de un marco de referencia de interacción social. Los roles del individuo normal y del estigmatizado no son meramente complementarios, sino que presentan ciertos paralelos y semejanzas notables. Algunas estrategias de adaptación desarrolladas en esta "práctica dramática" por parte del estigmatizado se desarrollan en tres aspectos. La primera establece que la gente trata de encubrirse y lo hace en ambas direcciones. Otra, es el psicodrama, en donde en determinados escenarios cambian los papeles y se desempeña el rol del normal, con significativas habilidades. Por último, está aquella situación en que el individuo estigmatizado puede desarrollar ambos roles, el del normal y el del estigmatizado, proveniente de burlas en privado ${ }^{76}$.

"Una persona estigmatizada es como cualquier otra que conoce el punto de vista que los otros tienen de personas como ella, y que se diferencia de estos, por tener una razón especial para resistir, la detracción provocada por el estigma en presencia

que proporciona el fundamento de una normalidad fantasma. "La naturaleza de un buen ajuste, es ahora evidente. Exige, que el individuo estigmatizado se acepte, alegre e inconscientemente igual que los normales, mientras, que al mismo tiempo, se aleja por voluntad de aquellas situaciones en las cuales los normales tendrían dificultad en fingir un tipo de aceptación similar": GofFman. Estigma. La identidad deteriorada, cit., p. 153.

75 Ibíd., p. 163.

76 Ibíd.,pp. 166-167. 
de los normales, y la facultad especial de expresarla cuando están ausentes"77. De esta manera, están en un mismo plano el estigmatizado y el normal, son parte el uno como el otro. El estigma termina por implicar no un conjunto de sujetos que se diferencian en dos grupos, sino un proceso social fundamental en donde cada individuo participa en ambos roles: el del estigmatizado y el del normal. Finalmente y atendiendo al concepto de categorías, GofFMAn establece que el normal y el estigmatizado no son personas, sino perspectivas dentro de una interacción social.

De otra parte, a lo largo del texto de 1963 el autor intenta esquivar la utilización del concepto de estigma ${ }^{78}$. Para GofFMAN hablar de desviado y de desviación supone que un determinado grupo de individuos que comparten ciertos valores se acoplen a una serie de normas sociales relativas a la conducta y a los atributos personales. El individuo divergente será el que no se adhiere a las normas, de divergencia, y a su peculiaridad ${ }^{79}$.

Dentro de este concepto existen varias clases de desviados: los intragrupales ${ }^{80}$, los endogrupales ${ }^{81}$, los desviados sociales ${ }^{82}$, los miembros de grupos minoritarios y las personas de clase baja. Estos, en determinadas ocasiones se encuentran como individuos estigmatizados, "inseguros de la acogida que los espera en la interacción cara a cara y profundamente implicados en las diversas respuestas a esta situación"83. Así para GOFFMAN, una comunidad desviada podría llegar a desempeñar las mismas funciones que lleva a cabo un desviado endogrupal para su grupo, pero, si bien esto puede ser teóricamente cierto, nadie hasta ahora parece haberlo demostrado.

77 Ibíd., p. 168.

78 Para GOFFMAN la palabra desviación (deviant) sustituye términos que eran usados por otras disciplinas, como en el caso del toxicómano. Este autor es reiterativo respecto al uso de conceptos y nombres establecidos a movimientos. Para él, no son más que etiquetas inventadas por gente que quiere encasillar un determinado comportamiento o forma de pensar. Cfr. WINKIN. Entrevista con ERVING GOFFMAN, cit., p. 212.

79 Ibíd., p. 175.

80 Es aquella relación de divergencia con el grupo, en donde la percepción que las personas del grupo tienen de él afecta la reestructuración de este espacio. La percepción de divergencia es de tal índole que impide la reestructuración grupal.

81 Un desviado endogrupal se representa con virtudes bufonescas. Ese individuo posee determinados atributos que lo establecen con un rol fundamental al interior del grupo.

82 La desviación social en GOFFMAN resultó ser un concepto innovador en la sociología de la desviación. Para él, un desviado social es aquel que se reúne en una subcomunidad o medio. "Son un tipo especial de divergentes. Si hablamos de un campo de indagación llamado desviación, quienes presumiblemente constituyen su núcleo son los desviados sociales. En él están las prostitutas, drogadictos, delincuentes, músicos de jazz, bohemios, gitanos, comparsas de carnaval, vagabundos, borrachos, gente de circo, jugadores empedernidos, vagabundos de playa, homosexuales y el mendigo de ciudad. Esta es la gente a quien se considera comprometida en cierto tipo de rechazo colectivo del orden social": GofFMAn. Estigma. La identidad deteriorada, cit., p. 178.

83 Ibíd., p. 181. 


\section{DE LAS CRÍTICAS A GOFFMAN Y OTRAS CUESTIONES}

Uno de los principales críticos de la Teoría del Estigma fue Denis ChapMan. En 1968 publica su Sociología y el estereotipo del criminal, cuya tesis fundamental radica en que la construcción de estereotipos se encuentra más allá de las mediaciones sociales o económicas existentes en una sociedad, es el resultado de síntesis sociales mediadas por prejuicios de los individuos. Para CHAPMAN, la teoría de GOFFMAN presenta cuatro grandes falencias en su estructura. La primera de ellas reside en la selección que se hace de cierto tipo de delito o desviación. Esta realiza suposiciones acerca de la existencia de los grupos o en algunos casos de subculturas, con poca evidencia, asumiendo que estos existen en todos los lugares y en todas las clases sociales ${ }^{84}$. Una segunda crítica se refiere a la constante dependencia de los datos subjetivos, lo que ocasiona que las generalizaciones realizadas sean respuestas dadas para todos los investigadores sociales. Una tercera discusión recoge que la teoría del estigma no trata con las funciones sociales de la estigmatización, de manera que el problema de las consecuencias sociales de la desestigmatizacíon queda anulado académicamente. Un último elemento con el que acaba CHAPMAN la crítica hacia GOFFMAN se relaciona con la debilidad de los estudios del delito organizado y las diversas organizaciones delictivas. La estigmatización, según CHAPMAN, presenta enormes problemas de teorización, que fueron olvidados por todos aquellos que plantearon el desarrollo de la selectividad en la estigmatización ${ }^{85}$.

Ahora bien, para CHAPMAN la Teoría del Estigma resultó ser compatible con el resto de teorías conocidas. Por tanto, según él, cuadraba con la teoría de la interacción simbólica y la identificación diferencial, además de ser compatible con la teoría de Merton y Cloward y OHLin, en tanto ellos prestaron atención a las presiones realizadas para alcanzar determinadas metas y oportunidades limitadas para ciertos grupos o personas. También fue factible con Sutherland, para quien la iniciación y confirmación de actividades delictivas viene de la asociación con personas delincuentes. Finalmente, la teoría tendría similitudes con el punto de vista tradicional, en donde el delincuente termina por ser diferente de las cualidades que le predisponen a determinadas conductas ${ }^{86}$.

Atendiendo entonces a la creación de la Teoría del Estereotipo ${ }^{87}$, CHAPMAN establece que esta comienza con el orden moral y la ley. No con las personas, sus

84 "La teoría de la subcultura criminal o delincuente surge en las circunstancias especiales de los EU, donde han existido corrientes o vaivenes sucesivos de inmigración cultural diferentes en áreas urbanas densas con un sistema de política administrativa peculiar y un sistema legal pluralista y a veces ingenuo". ChAPMAn, El estereotipo del delincuente y sus consecuencias sociales, cit., p. 166. Chapman, El estereotipo del delincuente y sus consecuencias sociales, cit., pp. 165-166.

86 Ibíd., p. 168.

87 Esta teoría presenta dos rasgos fundamentales: la descripción y la selección. La primera atiende a la descripción de actitudes malas y actos desastrosos a determinadas personas o clases sociales. 
características y sus conductas. "La ley y la moralidad seleccionan a las personas para desaprobar y castigarlas, algunas leyes y morales, seleccionan ciertos grupos y no otros" 88 . A pesar de tener consigo una serie de supuestos diferentes respecto al delincuente, el estereotipo y la persona etiquetada, estos no son necesariamente excluyentes. Así, tanto la Teoría del Estereotipo como la del Estigma dan puntos de vista que analizan estas categorías. "El primero lo ve como una víctima de la sociedad con contradicciones internas, con pluralidad moral y diferencias de clase. La segunda teoría lo ve como inicialmente diferente y la estigmatización amplifica sus diferencias y a través de la autodefinición se dirige a un subgrupo delictivo o desviado. La primera teoría ve a la sociedad como área del problema, la segunda, aunque reconoce el problema social, concentra su interés en los delincuentes y en la subcultura delictiva" 89 . De esta forma -y en un sentido más amplio-, CHAPMAN señala que la criminología terminó por incluir no un desarrollo científico de la conducta, sino una simple extensión de los datos a los cuales se les aplicaron los enfoques más tradicionales.

Chapman no fue el único que desde un sentido más amplio discutió las elaboraciones conceptuales e investigativas de la sociología de la desviación. Autores como TAYLOR WALTON y YOUNG contribuyeron con su crítica demoledora a revisar algunos planteamientos de la teoría del etiquetamiento. Estos autores, apoyados en W. Mills, Mankoff y Gouldner plantearon los puntos más frágiles de la Teoría del Etiquetamiento. Cuatro fueron las grandes críticas que se agruparon desde la Nueva Criminología: 1. La conciencia como centro de modificación de la naturaleza del acto desviado. En este apartado se estableció que la desviación no era una cualidad del acto cometido por la persona, sino una consecuencia de la aplicación que otros hacían de normas y sanciones a un delincuente. Para ellos, los desviados, como los demás actores sociales, terminaron por cargar de una serie de significados todos sus actos, un significado que no se reinventaba cada vez que las personas realizaban un acto físico. Así, "la mayor parte de los actos desviados, y especialmente los delictivos, son actos físicos". Entonces, "la mayor parte de los actos desviados, y especialmente los delictivos, son actos físicos que tienen significados sociales. [Para la Nueva Criminología] no se actúa en un mundo libre de significados"90 . 2. La desviación no solo se estudia en función de la reacción social. Para los teóricos del etiquetamiento se suele dar una confusión entre las definiciones y concepciones de conducta, acción y desviación. Por tanto, las mismas adolecieron de un desarrollo sistemático, que trajo una teoría de la conducta desviada unilateral e incongruente.

La segunda, a la selección realizada por el sistema administrativo de personas débiles y pobres que tienen una descripción per se.

88 Ibíd., p. 173.

89 Ibíd., p. 180.

90 TAylor, Walton y Young. La Nueva Criminología: contribución a una teoría social de la conducta desviada, cit., p. 163. 
3. Centralismo en la desviación secundaria. La división entre desviación primaria y secundaria ocasionó una concentración excesiva en estos conceptos, olvidando una explicación plenamente social de cómo se origina el comportamiento desviado. "Lo que los teóricos de la reacción social dicen es que el desviado secundario acepta su desviación por motivos diferentes a los de su acción original. Este tipo de análisis de la aceptación de la propia desviación nos parece falto de fundamento y cargado de supuestos psicológicos injustificados. [...] Gran parte de este enfoque deja de lado el problema de la desviación inicial y pone en cambio un énfasis dudoso en el impacto psicológico de la reacción social"91-92.4. Enfoque ahistórico y psicológico. Se critica la peculiar fascinación de la Teoría del Etiquetamiento por elaborar una explicación de por qué algunas personas llegan a ser delincuentes irredimibles y otras no. Las explicaciones dadas por el enfoque de la reacción social serían a todas luces ahistóricas y psicológicas. Por tanto, es fundamental considerar que las causas de la desviación se encontraban en desigualdades sociales más amplias de poder y autoridad. "La mayor parte de comportamientos desviados corresponde a acciones conscientes de los individuos destinados a hacer frente a los problemas generados por una sociedad sobre la cual ejercen escaso control. Si la desviación inicial (la infracción de normas) se explica como resultado de impulsos fortuitos que no reconocen causas primarias, se tiende a negar que esas soluciones desviadas tengan significado real para el individuo"93.

Otros autores más actuales, como Downes y Rock desarrollaron una crítica interesante en dos puntos. Por un lado, recogieron las críticas que se plantearon desde diferentes disciplinas entrada la mitad del siglo xx; por otro, los autores realizaron su propia mirada respecto al interaccionismo. La primera ola de críticas la resumieron en cuatro direcciones: 1) El cuestionamiento al estatus científico. "El interaccionismo es heredero de los supuestos y las prácticas de la Escuela de Chicago y se resiste a una metodología lógico-deductiva ordenada" "94. 2) Una crítica hecha desde la fenomenología. Para ellos, el interaccionismo falló en su tarea fundamental, no capturó con el vocabulario el rol de desviación y proceso. Los roles -afirmaron- son invenciones sociológicas y no rasgos del mundo social. 3) Una crítica dirigida al término mismo de desviación, por entender que este consistió en un artificio sociológico y no en un fenómeno natural que el sociólogo descubra en un estado imperturbado. Los interaccionistas no definieron la desviación con precisión ${ }^{95}$. 4) Una a la visión

91 "Si deseamos sostener que los individuos son, a la vez, algo determinado pero también determinante, entonces tendremos que construir un modelo evolutivo congruente que tenga en cuenta esta concepción del hombre y la ubique dentro del análisis total de los conceptos sociales, y no, simplemente, dentro de uno de sus aspectos": ibíd., p. 163.

92 Ibíd., p. 163.

93 Ibíd., p. 171.

94 DownES Y Rock. Interaccionismo simbólico, cit., p. 286.

95 "El de desviación se ha convertido en un concepto impreciso cuyos detalles han sido aportados por estudios de acontecimientos concretos. El interaccionista no se molestaría en amalgamar o 
de la criminología radical apoyada fuertemente en el marxismo y la sociología del conflicto. Para ellos, "el interaccionismo menciona al pasar el tema de poder, y ha ofrecido historias de elaboración de leyes y control. [...] Para los interaccionistas los grupos delictivos cambian ocasionalmente, de acuerdo con las situaciones y los lugares, y el estudio intensivo de un grupo delictivo no puede aportar la verdad acerca de todos los delincuentes" 96 .

Las críticas formuladas por Downes y Rock, lejos del anterior grupo, se presentaron como menos duras a las realizadas por los teóricos de la Criminología Radical. Para ellos, el interaccionismo no estaba exento de ambigüedades. Por ende, había un espacio suficiente para la coexistencia de teorías contrapuestas dentro de una división intelectual del trabajo. Finalmente, atendiendo a las críticas de la Nueva Criminología, afirmaron que "La concepción de que el Estado puede ser opresivo y protector de los intereses de clase no tiene relación alguna con la validez o el interés del abordaje de la rotulación" ${ }^{\prime 97}$. La teoría de la reacción social -para la Nueva Criminología- pudo ser válida en abstracto, pero no pudo vincular la gravedad de la reacción social ante diferentes períodos históricos y dentro de distintos ordenamientos sociales.

\section{REFLEXIONES FINALES}

GOFFMAN y su libro Estigma realizaron innumerables aportes a la sociología de la desviación. Este autor presenta especial interés en términos de su rico aporte conceptual. Por ende, incluirlo en determinada categoría intelectual resulta particularmente complejo. Tanto Internados $^{98}$ (1961) como Estigma (1963) comparten la construcción del concepto de identidad personal. Dicha construcción está mediada por encubrimientos, técnicas y espacios, en donde el estigmatizado y el normal recrean sus contactos mixtos. Conceptos como el de desviado normal o el de desviado social resultan ser bastante novedosos en el inicio de la segundad mitad del siglo XX.

Son innumerables las críticas que se han realizado al pensamiento de GofFMAN. Este mostró una singular ambivalencia en las confrontaciones de la investigación teórica: "Por una parte, concentra su atención en la interacción cara a cara. Por otra, declara querer abrir una de las perspectivas sociológicas mediante la que se puede

clasificar todos esos detalles. Más bien, la concepción se construye de manera creciente y gradual, incluyendo casos marginales y acaso absurdos": ibíd., p. 288.

96 Ibíd., p. 289.

97 Ibíd., p. 292.

98 Aunque no puede considerarse a GOFFMAN dentro de la antisiquiatría, las contribuciones que hizo con el libro Internados fueron fundamentales. Para los antisiquiatras la enfermedad mental no era exclusivamente una cuestión determinada, técnica u objetiva. Detrás de esta se escondían conflictos sociales y políticos que no se develaban. Cfr. LARRAURI. La herencia de la criminología crítica, cit., p. 49. 
estudiar la vida social a través de la elaboración de un esquema de referencia, que pueda utilizarse en el análisis de todo sistema social, ya sea familiar, industrial o mercantil" 99 . Pese a esto y a su convulsionado entorno académico de movimientos intelectuales, el análisis centrado en categorías, rico descriptivamente y sin grandes pretensiones intelectuales, es lo que hace de Estigma. La identidad deteriorada un texto necesario en las discusiones de sociología de la desviación y del interaccionismo simbólico.

\section{BIBLIOGRAFÍA}

AleXAnder, J. Las teorías sociológicas de la Segunda Guerra Mundial. Barcelona, Gedisa, 1992.

Anitua, G. I. Historia de los pensamientos criminológicos. Buenos Aires, Editorial Puesto, 2005.

BECKER, H. ¿De qué lado estamos? En: AA.VV. Estigmatizacion y conducta desviada. Maracaibo, Universidad de Zulia 1962, pp. 19-38.

Caballero, J. J. La interacción social en el pensamiento sociológico de Erving Goffman. Revista Espacios Públicos, vol. 14, n. ${ }^{\circ}$ 31, mayo/agosto, México, Universidad Autónoma del Estado de México, 2011, pp. 158-175.

Chapman, D. El estereotipo del delincuente y sus consecuencias sociales [1973]. En: AA.vv. Estigmatización y conducta desviada. Maracaibo, Universidad de Zulia, 1962, pp. 161-186.

Downes, D. y P. Rock. Interaccionismo simbólico. En: Sociología de la deviación. Barcelona, Gedisa, 2011, pp. 261-293.

ERIKSON, K. Notas sobre la sociología de la desviación. En: AA.VV. Estigmatización y conducta desviada. Maracaibo, Universidad del Zulia, 1962, pp. 39-52.

Goffman, E. Estigma. La identidad deteriorada. Buenos Aires, Amorrortu, 2010.

Herrera, M. y R. Soriano. La teoría de la acción social en Erving Goffman. Revista Papers de Sociología n. ${ }^{\circ}$ 73. Barcelona, Universidad de Barcelona, 2004, pp. 59-79.

KITSUSE, J. Reacción de la sociedad ante la conducta desviada: problemas de teoría y método. En: AA.vv. Estigmatización y conducta desviada. Maracaibo, Universidad de Zulia, 1962, pp. 53-72.

99 Herrera y Soriano. La teoría de la acción social en ERVING GofFMAn, cit., p. 59. 
LARRAURI, E. La herencia de la criminología crítica. México, Siglo XXI, 1992, pp. 25-65.

LEMERT, E. Desviación primaria y secundaria. En: AA.vV. Estigmatización y conducta desviada. Maracaibo, Universidad del Zulia, 1962, pp. 97-104.

MARRERo GuILlamón, I. Descentrar el sujeto. ERVING GoFFMAn y la teorización del sujeto. Revista Internacional de Sociología (RIS), Vol. 70, n. ${ }^{\circ}$ 2, mayo-agosto 2012, Instituto de Estudios Sociales Avanzados de Andalucía. Granada pp. 311-326.

TAYLOR, I.; P. WALTON y J. Young. La reacción social, aceptación de la propia desviación y la carrera desviada. En: La Nueva Criminología: Contribución a una teoría social de la conducta desviada. Buenos Aires, Amorrortu, 2007, pp. 167-201.

WINKIN, Y. Entrevista con ERVING GofFMAN [1977]. En: Los momentos y sus hombres. Barcelona, Paidós, 1991. 